\title{
Escolha vocacional em adolescentes: contributos para um programa de competências sócio-emocionais
}

\author{
Sara Medeiros Soares*, Suzana Nunes Caldeira**, Marina Sousa* \& Célia Barreto Carvalho*** \\ *Universidade dos Açores, Portugal \\ **Universidade dos Açores - CICS.NOVA.UAçores, Portugal \\ ***Universidade dos Açores e Centro de Investigação do Núcleo de Estudos e Intervenção Cognitivo-Comportamental, Portugal
}

\begin{abstract}
Resumo
Este estudo pretendeu compreender em que medida a participação em duas sessões de um programa de competências sócio-emocionais terá tido impacto na atitude dos jovens face à escolha vocacional. A amostra contou com 220 alunos do $8 .^{\circ}$ ano de escolaridade, de cinco escolas da ilha de S. Miguel. Os dados foram recolhidos através de um protocolo que continha escalas e questionários e de um Diário de Bordo. Dos resultados obtidos através análise de conteúdo, observaram-se melhorias ao nível do conhecimento dos fatores inerentes ao processo de escolha vocacional e à relação das emoções com a decisão vocacional.
\end{abstract}

Palavras chave: escolha vocacional, desenvolvimento de competências, implementação de um programa, inteligência emocional

\section{Introdução}

\section{Escolha Vocacional}

A escolha vocacional pode ser encarada como a ação de "eleger" uma alternativa em detrimento de outra e de iniciar um plano de realização de um determinado objetivo a curto prazo (Rassin \& Muris, 2005). Crites (1969) define a escolha vocacional como uma resposta verbal, que compreende uma mudança comportamental podendo ser observada direta ou indiretamente (i.e., escrever, falar, procurar e avaliar informação), relacionada com a vida, pessoal e profissional, futura. A escolha face a projetos vocacionais futuros implica a intenção de escolher um determinado objetivo, pressupondo uma decisão e a ponderação de várias alternativas, tendo em conta a consideração das possibilidades de sucesso em cada uma delas (Santos, 2005). Os jovens, por vezes, têm dificuldade em fazer escolhas face ao futuro, isto pode dever-se a fracas oportunidades de desenvolvimento pessoal e vocacional, ao fraco aproveitamento dessas mesmas oportunidades pelos sujeitos ou à influência negativa de determinadas experiências sociais e culturais (Taveira, 2001). A escolha vocacional está presente em todos os indivíduos desde que nascem até morrerem, é um processo que acompanha o sujeito ao longo de todo o seu desenvolvimento.

\section{Fatores que exercem influencia na escolha vocacional}

Zunker (1986) defende que, no ato de tomar decisões relativas à carreira, é preciso ter em consideração fatores internos e externos. Hackett e Byars (1996), referem que as aspirações e as expetativas de auto-eficácia, o género, a ansiedade e a indecisão (fatores internos), têm forte preponderância no ato de tomar decisões. A auto-eficácia, que é a avaliação que o sujeito faz da sua capacidade para realizar determinadas tarefas, pode exercer forte influência nas decisões, funcionando como um recurso ou obstáculo ao desenvolvimento vocacional (Pocinho, Correia, Carvalho \& Silva, 2010). O género é apontado como um fator interno importante nos processos de tomada de decisão (Leong \& Brown, 1995), uma vez que parece diferenciar os jovens em termos da exploração e indecisão vocacional, e, assim, na elaboração e concretização de projetos vocacionais (Taveira, 2000). O locus de controlo e a ansiedade são, também eles, apontados na literatura existente como intervenientes no processo de tomada de decisão, visto que alunos com um locus de controlo externo ou com excessiva ansiedade têm dificuldades na tomada de decisão de carreira (Newman, Fuqua, \& Seaworth, 1989). A indecisão é vista como um fator que exerce influência na decisão vocacional, porque sujeitos indecisos vocacionalmente caracterizam-se por ter pouca motivação e iniciativa para explorar alternativas ocupacionais e quando tomam decisões estas são impulsivas e baseadas em estratégias de tentativa e erro; possuem também uma perspetiva temporal restrita ao presente, logo têm grandes dificuldades para imaginar o futuro (Magalhães \& Redivo, 1998). Os fatores externos podem tornar mais difícil o processamento da informação, tanto para a resolução de problemas que o indivíduo encara como para a tomada de decisão de carreira (Sampson, Reardon, Peterson, \& Lenz, 2004). A família é apontada como um dos principais fatores que ajuda ou dificulta no momento da escolha e na decisão do jovem (Super, 1990). Super (1990) afirma que o contexto familiar fornece oportunidades para crianças e jovens se identificarem com determinados modelos de papéis adultos, cria necessidades e modela valores. A escola, por ser o lugar onde os adolescentes passam a maior parte do seu tempo, está presente, tanto no desenvolvimento vocacional do jovem (Patton \& McMahon, 1999), como no seu processo de socialização e na formação da sua personalidade (Groisman \& Kusnetzoff, 1984), aspetos que contribuem de forma fundamental para a construção do projeto de vida.

\section{Competências sociais e emocionais e a escolha vocacional}

O interesse pela promoção das competências sociais e emocionais desenvolveu-se a partir da consciência de 
que estas competências são essenciais para alcançar o sucesso (Elksnin \& Elksnin, 2004) não só académico, mas também, na vida adulta, dadas as crescentes exigências e desafios que a sociedade atual coloca (Payton, Wardlaw, Graczyk, Bloodworth, Tompsett, \& Weissberg, 2000) aos jovens, tanto do ponto de vista cognitivo como também nos aspetos social e emocional (Brackett \& Katulak, 2006). McFall (1982) define competência social como um conceito teórico de carácter avaliativo que reflete sempre um juízo do próprio ou dos outros (pessoas significativas) acerca das capacidades específicas que permitem a uma pessoa executar determinadas tarefas sociais. Para Vaughn e Hogan (1994) a competência social é definida por como um constructo multidimensional onde o sujeito lida com as transformações sociais, interage com o meio ambiente, responde à complexidade da vida e adequa as respostas comportamentais aos diferentes contextos. No que se refere às competências emocionais, estas definem-se como sendo a capacidade de adaptação do sujeito a uma complexidade de situações, de forma funcional, através de respostas ajustadas e eficazes (Silva, 2011). O desenvolvimento destas competências permite ao indivíduo mostrar-se capaz de identificar as suas emoções, refletir sobre as suas causas e respetivas influências e compreender como elas condicionam a sua conduta, com vista à gestão/regulação dessas mesmas emoções (Mayer \& Salovey, 1997). Matsumoto, Yoo e Nakagawa, (2008) afirmam a relevância das emoções e o seu papel na ligação íntima com as competências sociais, indicando-as como forma de regular e manter as relações interpessoais. As competências sociais relacionam-se com a tomada de decisão dado que sujeitos que interagem de forma positiva com o contexto onde se inserem, tomam decisões conscientes e refletidas (Palmini 2004). Sujeitos com elevados níveis de regulação emocional, apresentam um melhor relacionamento interpessoal, tomam decisões mais ajustadas, portadoras de mais bem-estar, tanto a nível pessoal como na atividade profissional.

\section{Programas de competências sociais e emocionais}

O processo de ensino-aprendizagem das emoções e o desenvolvimento de competências sociais e emocionais tem como finalidade o desenvolvimento integral do indivíduo, procurando aliar componentes da cognição e dos afetos (Ferrandiz, Bermejo, Fernández, Sainz, Valverde \& Araújo, 2014). A nível internacional é importante fazer referência ao programa "SEL - Social and Emotional Learning" - de Elias e colaboradores (Raimundo, 2012) que contribui para o processo de aprendizagem efetiva de competências sociais e emocionais e, ainda, para a aplicação desses conhecimentos, atitudes e comportamentos na regulação das emoções, na empatia com os outros, nas tomadas de decisão responsáveis, no estabelecimento de relações interpessoais saudáveis e na forma como se lida com situações de conflito e de stress (Raimundo, 2012). Os resultados demonstram o efeito benéfico destes programas na redução de problemas sociais e emocionais e no aumento de competências emocionais e sociais em crianças e adolescentes (Teixeira, 2010). No contexto nacional, em 2000, Pereira e Moreira apresentaram um estudo centrado nos resultados relativos à implementação de um programa longitudinal designado “Crescer a Brincar”. O programa visou possibilitar às crianças saber mais acerca dos seus sentimentos, pensamentos e projetos de vida. Os resultados evidenciaram uma tomada de decisão mais adequada e níveis mais elevados de assertividade nas crianças do grupo experimental, comparativamente com as do grupo de controlo (Raimundo, 2012). A nível nacional importa fazer referência, ainda, ao programa de intervenção SEL “Devagar se vai ao Longe” da autoria de Raimundo (2007, referido por Raimundo, 2012), como exemplo de um programa Português baseado nos princípios orientadores da CASEL. Este apresentou-se como um programa universal de promoção de competências sócioemocionais em contexto escolar. Os seus resultados mostram ganhos significativos em algumas competências sócioemocionais (autocontrolo, relações com os pares e competência social). Ainda, o Programa "À Conquista” concebido e aplicado por nós e colaboradores, nos Açores (Soares, Sousa, Amaral, Correia, Caldeira \& Carvalho 2014), tendo embora por objetivo central contribuir para o desenvolvimento de jovens convocando as suas qualidades e capacidades para as escolhas vocacionais, não deixa de contemplar nas suas sessões a promoção das competências sócio-emociais, pela importância que as mesmas têm no ato de tomar decisões (Palmini 2004). Os resultados deste programa, aplicado ainda em registo “experimental” foram encorajadores, constituindo um estímulo para a continuação e implementação de futuras edições. Estas e outras intervenções têm apontado para os efeitos positivos de programas preventivos que investem na aprendizagem social e emocional resultando na diminuição de problemas e no aumento de habilidades emocionais e sociais (Teixeira, 2010). Além dos esforços que se têm realizado, é recomendável que as intervenções realizadas sejam inseridas nos programas curriculares das escolas, não sendo apenas pontuais, pois as competências carecem de tempo para serem trabalhadas corretamente.

\section{Método}

\section{Objetivo}

O presente estudo teve como objetivo compreender se a exposição a duas sessões do programa de competências sociais e emocionais "Alinha com a Vida”, interfere com a atitude dos adolescentes face à escolha vocacional.

\section{Participantes}

O presente estudo contou com 220 participantes do sexo feminino e masculino, tendo por base uma população escolar constituída por 11 turmas do $8^{\circ}$ ano de escolaridade, provenientes de cinco escolas do Ensino Básico da ilha de São Miguel - Açores (Portugal). A média de idades dos participantes corresponde aos 13.54 anos, sendo a idade mínima de 12 anos e a idade máxima de 18 anos. 


\section{Instrumento}

A recolha de dados foi efetuada a partir de um protocolo composto por várias escalas e questionários (avaliação quantitativa) e de um Diário de Bordo (avaliação qualitativa), de modo a avaliar os jovens relativamente às competências sócio-emocionais. No presente estudo, só se apresentarão os resultados da vertente qualitativa, razão pela qual este ponto é circunscrito à descrição do Diário de Bordo. Bogdan e Bilken (1994, p.150) referem que os registos feitos pelo investigador são "o relato escrito daquilo que o investigador ouve, vê, experiencia e pensa no decurso da recolha e refletindo sobre os dados de um estudo qualitativo”. Como forma de facilitar o preenchimento do Diário de Bordo, definiram-se elementos orientadores, de acordo com o que se pretendia apreender nas sessões referentes à tomada de decisão, nomeadamente: aquisição de conhecimentos por parte dos alunos ao nível da tomada de decisão e o papel das emoções no processo de tomada de decisão.

\section{Procedimento}

\section{Recolha.}

Antes da implementação do programa de competências sócio-emocionais - “Alinha com a Vida”- foi feito um pedido de autorização à Secretaria Regional da Educação e Formação e, após a aceitação do pedido, foi entregue aos Conselhos Executivos das escolas uma carta de apresentação do trabalho onde se solicitava a adesão das mesmas. A recolha dos dados realizou-se no $2^{\circ}$ período do ano letivo de 2013/2014. O programa teve um caráter coletivo (por turma) e foi aplicado em contexto sala de aula. As sessões foram realizadas na disciplina de Cidadania, na presença do professor, com uma duração de 90 minutos e num registo semanal. A participação dos jovens foi voluntária e anónima, tendo sido apresentado um consentimento informado. A aplicação do programa teve início em janeiro de 2014 e terminou em abril do mesmo ano.

Análise.

Utilizou-se a análise de conteúdo como técnica (ou conjunto de técnicas) para tratamento da informação recolhida através do Diário de Bordo. Partindo de uma primeira análise do conjunto de elementos orientadores, contidos nos Diários de Bordo de cada sessão do programa, elaborou-se um sistema de categorias, utilizando uma metodologia de análise de conteúdo, que é apresentada em seguida. Relativamente às duas sessões em foco neste trabalho, o procedimento de análise de conteúdo consistiu numa primeira leitura vertical de todos os registos efetuados no âmbito das duas sessões sobre a tomada de decisão, que permitiu a classificação dos temas pertinentes e conceitos chave, resultando num subgrupo de categorias que podem guiar a análise por diversos caminhos (Amado, 2013). De seguida passa-se a apresentar o sistema de categorias e subcategorias que permitiu organizar a informação recolhida nos Diários de Bordo, para a respetiva análise de conteúdo. Como categoria temos: 1) a aquisição de conhecimentos por parte dos alunos ao nível da tomada de decisão e 2) o papel das emoções no processo de tomada de decisão. A categoria 1 deu origem às seguintes subcategorias: 1.1) tomada de decisão; 1.2) exploração vocacional; 1.3) fatores internos que influenciam o processo de tomada de decisão; 1.4) fatores externos que influenciam o processo de tomada de decisão. Por fim aplicaram-se procedimentos de tratamento quantitativo (\%) aos dados qualitativos.

\section{Intervenção.}

O programa “Alinha com a Vida” tem como objetivo desenvolver competências que permitam aumentar a flexibilidade dos jovens e ajudá-los a lidar melhor com a imprevisibilidade e a mudança, transformando os obstáculos em desafios. A estrutura do programa assentou em vários modelos em função dos temas tratados. Adotaram-se os três modelos basilares da Inteligência Emocional (IE) (modelo de IE de Mayer e Salovey; modelo das emoções de Ekman; modelo evolucionário de Guilbert) para as sessões relativas às emoções e à inteligência emocional. Nas duas sessões que se descrevem em profundidade no presente estudo, sobre a temática da escolha vocacional, teve-se por base o modelo de desenvolvimento da carreira de Super. A sessão “Tu Decides!” tem como objetivo relacionar as emoções trabalhadas nas sessões anteriores com os processos de tomada de decisão. Assim sendo, pretende-se que os adolescentes aumentem a sua capacidade de identificar, diferenciar e regular as emoções, de modo a que possam mobilizar estas mesmas emoções aquando das várias tomadas de decisão do dia-a-dia. Relembram-se as várias emoções trabalhadas ao longo das sessões, bem como as suas funções; é também explicado aos jovens o que é a tomada de decisão e a sua importância nas várias situações do dia-a-dia. Realizam-se duas dinâmicas, nomeadamente "Põe-te no meu lugar", que pretende que os jovens reflitam sobre o conceito da empatia e compreendam a sua importância nas relações sociais e pessoais e nos processos de tomada de decisão, e “A decisão final”, que pretende dotar os adolescentes de capacidades para lidarem com tomadas de decisão, refletindo acerca da importância das emoções e da regulação emocional nas escolhas do dia-a-dia. A sessão “À exploração do meu futuro vocacional” tem como objetivos que os jovens tomem contacto com o conceito de exploração e a sua importância no processo de tomada de decisão vocacional; que conheçam os fatores internos e externos a ter em conta durante o processo de exploração; e relembrem a relação existente entre as emoções e o processo de tomada de decisão. Explica-se aos jovens o conceitos de exploração; os fatores que influenciam o processo de tomada de decisão vocacional; e a relação entre as emoções e a decisão vocacional. Realiza-se um debate, acerca dos interesses e aptidões dos jovens e realiza-se a dinâmica - "Eu decido ou tu decides por mim!”- que dá a conhecer os fatores que influenciam o processo de tomada de decisão vocacional. As atividades desenvolvidas ao longo destas duas sessões, bem como de todo o Programa, foram expostas escrita e oralmente, com recurso a audiovisuais (PowerPoint e vídeos temáticos); à reflexão e discussão com todos os elementos das turmas; auto-reflexão; auto-registo; 
roleplaying; e brainstorming. Todas as sessões foram avaliadas através de registos de caráter qualitativo.

\section{Resultados}

Os resultados por categoria (e subcategoria) são sintetizados no Quadro 1, mostrando-se "respostas tipo" e a respetiva percentagem de incidência.

Tabela 1.

Resultados por Categoria e Subcategoria

Categoria 1 Aquisição de conhecimentos por parte dos alunos ao nível da tomada de decisão

\begin{tabular}{|c|c|c|}
\hline \multirow[t]{2}{*}{ Subcategorias } & Resposta tipo & $\begin{array}{c}\text { Incidência } \\
\%\end{array}$ \\
\hline & $\begin{array}{l}\text { quando temos um problema } \\
\text { com duas ou mais soluções e não } \\
\text { sabemos qual a solução que } \\
\text { devemos tomar" }\end{array}$ & 54.54 \\
\hline \multirow[t]{3}{*}{$\begin{array}{l}\text { 1.1) Tomada de } \\
\text { decisão }\end{array}$} & $\begin{array}{l}\text { quando só há uma alternativa } \\
\text { temos de decidir se escolhemos } \\
\text { ou não }\end{array}$ & 36.36 \\
\hline & $\begin{array}{l}\text { decidir implica pensar de forma } \\
\text { consciente, decidir pensando nas } \\
\text { consequência }\end{array}$ & 36.36 \\
\hline & $\begin{array}{l}\text { conhecer-se para ver o que } \\
\text { gosta mais }\end{array}$ & 36.36 \\
\hline \multirow[t]{4}{*}{$\begin{array}{l}\text { 1.2) Exploração } \\
\text { vocacional }\end{array}$} & $\begin{array}{l}\text { informar-se para tomar boas } \\
\text { decisões, para isso temos de } \\
\text { procurar" }\end{array}$ & 36.36 \\
\hline & descobrir & 27.27 \\
\hline & saber coisas novas & 27.27 \\
\hline & nós próprios & 45.45 \\
\hline \multirow{3}{*}{$\begin{array}{l}\text { 1.3) Fatores internos } \\
\text { que influenciam o } \\
\text { processo de tomada de } \\
\text { decisão }\end{array}$} & o que sentimos desconforto & 9.09 \\
\hline & o que quero fazer & 9.09 \\
\hline & o que tenho jeito & 18.18 \\
\hline $\begin{array}{l}\text { 1.4) Fatores externos } \\
\text { que influenciam o } \\
\text { processo de tomada de } \\
\text { decisão" }\end{array}$ & $\begin{array}{l}\text { as pessoas de fora, por exemplo } \\
\text { os pais; os amigos; a família; } \\
\text { professores; namorados" }\end{array}$ & 81.81 \\
\hline
\end{tabular}

Categoria 2 "O papel das emoções na tomada de decisão"

$$
\begin{aligned}
& \text { Resposta Tipo } \\
& \text { com boas decisões sentimos emoções } \\
& \text { boas } \\
& \text { se a emoção for negativa ele vai se } \\
& \text { lembrar do que aconteceu e não toma a } \\
& \text { mesma decisão da próxima vez } \\
& \text { as emoções servem para nos sentirmos } \\
& \text { alegres quando temos que tomar boas } \\
& \text { decisões } \\
& \text { eu acho que é porque se a gente se sentir } \\
& \text { tristes vamos tentar adiar as coisas e se } \\
& \text { estivermos bem vamos tentar resolver as } \\
& \text { coisas } \\
& \text { se a emoção da decisão for positiva da } \\
& \text { próxima vez é mais fácil decidir }
\end{aligned}
$$$$
\text { Incidência }
$$

Considerando quatro níveis de apreciação da incidência, a saber, muito elevado (>75), médio (50-74), baixo (25-49) e muito baixo ( $<25 \%)$, observa-se que "respostas tipo" dos jovens, na categoria 1) “Aquisição de conhecimentos por parte dos alunos ao nível da tomada de decisão” oscilam entre uma incidência muito

elevada ( $>75$ ), na subcategoria 1.4) Fatores externos que influenciam o processo de tomada de decisão, a muito baixa ( $<25 \%$ ) na subcategoria 1.3) Fatores internos que influenciam o processo de tomada de decisão. Na categoria 2) "O papel das emoções na tomada de decisão", pode-se observar que as "respostas tipo" dos jovens reúnem um baixo (25-49\%) ou muito baixo nível ( $<25 \%$ ) de incidência.

\section{Discussão}

Segundo Rassin e Muris (2005) a escolha vocacional é definida como a ação de "eleger" uma alternativa em detrimento de outra. Ora, as respostas dos jovens enquadram-se na definição apresentada, ao exibirem percentagens médias (54.54\%) na subcategoria 1.1) “tomada de decisão”. Através do acima exposto, podemos inferir que os conteúdos trabalhados na sessão, acerca do que é a escolha/decisão vocacional, foram apreendidos pelos jovens. Relativamente à subcategoria 1.2) “exploração vocacional”, embora tenha tido percentagens relativamente baixas (36.36\% a $27.27 \%$ ), as respostas dada pelos participantes vão ao encontro da definição de Taveira (2005), para quem a exploração envolve atividades de experimentação, investigação, tentativa e erro, procura e questionamento, perspetiva e teste de hipóteses. Os comportamentos de exploração e consequentes tomadas de decisão têm sido considerados fatores protetores do processo de transição para a vida adulta (Savickas, 1985), e neste sentido, quanto mais informados os jovens estiverem acerca do que é o processo de exploração vocacional, melhor se sentirão face às escolhas vocacionais que tiverem de tomar futuramente. Nas subcategorias 1.3) "fatores internos que influenciam o processo de tomada de decisão" e 1.4) "fatores externos que influenciam o processo de tomada de decisão" observa-se um grande diferencial nas percentagens das "respostas tipo" obtidas (de 9,09\% a 81.81\%). Este é um aspeto a que se deve dar atenção, pois, como dizem Faria, Taveira e Saavedra (2008) este conjunto de fatores (internos e externos) exerce influência no ato de decidir, pelo que importa trabalhar estas variáveis, ultrapassando a mera definição das mesmas e compreendendo o seu alcance. As respostas dadas à categoria 2) "O papel das emoções no processo de tomada de decisão", apresentam percentagens tendencialmente baixas e muito baixas (25-49\% e $<25 \%$ ). Embora alguns jovens aparentem mostrar conhecimento sobre as emoções e o papel que estas podem desempenhar no processo de escolhas, esta é uma área que parece merecer ser mais trabalhada. A escolha relativamente ao futuro é uma decisão muito importante que irá ter implicações para a carreira e para a vida em geral do jovem. Afigura-se útil a realização de programas que aliem as competências sócio-emocionais ao processo de escolha vocacional visto que, tal como sugerido neste e noutros estudos estas competências têm influência no ato de decidir, contribuindo para que os jovens tomem decisões mais conscientes e se sintam melhor com as suas escolhas relativamente ao futuro. Os resultados permitem concluir que os objetivos previamente definidos para o presente estudo foram atingidos. A 
definição de escolha vocacional e de exploração vocacional, bem como a função das emoções na tomada de decisão foram apreendidas pelos jovens. Assim, considera-se que os resultados das duas sessões do "Alinha com a Vida" que incidem sobre o tópico da escolha e, tomada de decisão vocacional são encorajadores e contribuem para afirmar o valor do programa.

\section{Referências}

Amado, J. (2013). Manual de Investigação Qualitativa em Educação. Coimbra: Imprensa da Universidade de Coimbra.

Bogdan, R., \& Biklen, S. (1994). Análise de conteúdo. Investigação qualitativa em educação: Uma introdução à teoria e aos métodos. Porto: Porto Editora.

Crites, J. O. (1969). Vocational psychology. New York: McGraw-Hill.

Elksnin, L., \& Elksnin, N. (2004). The social-emotional side of learning disabilities. Learning Disability Quarterly, 27, pp.3-8.

Faria, L; Taveira, M.C. \& Saavedra, L.M. (2008). Exploração e decisão de carreira numa transição escolar: Diferenças Individuais. Revista Brasileira de Orientação Profissional, 9(2), pp. 17-30.

Ferrándiz, C., Bermejo, R., Fernández, M. S., Valverde, J. \&Araújo, A. (2014). Inteligência Emocional: Aplicações e Implicações Educativas. In Almeida, L. \& Araújo, A. (1 $\left.{ }^{\mathrm{a} E d}\right)$, Aprendizagem e sucesso escolar: Variáveis pessoais dos alunos (pp.137-171). Braga: ADIPSIEDUC.

Groisman, M \& Kusnetzoff, J. C. (1984). Adolescência e saúde mental. Porto Alegre: Artes Médicas.

Hackett, G., \& Byars, A. M. (1996). Social cognitive theory and the career development of African American women. Career Development Quarterly, 44(4), 322-340.

Leong, F. T., \& Brown, M. T. (1995). Theoretical issues in cross-cultural career development: Cultural validity and cultural specificity. Em W. B. Walsh \& S. H. Osipow (Eds.), Handbook of vocational psychology: Theory, research and practice (2th ed.) (pp. 142-180). New-Jersey: Laurence Erlbaum Associates.

Magalhães, M. \& Redivo, A. (1998). Re-opção de curso e maturidade vocacional. Revista Semestral Da Associação Brasileira De Orientadores Profissionais ABOP, 2(2), 7-28.McFall, R.M. (1982). A review and a reformulation of the concept of social skills. Behavioral Assessment, 4, pp.1-33.

Matsumoto, D., Yoo, S.H. \& Nakagawa, S., (2008). Culture, Emotion Regulation, and Adjustment. Journal of Personality and Social Psychology, 94 (6), 925-937.

Mayer, J. D. \& Salovey, P. (1997). Emotional development and emotional inteligence. Nova Iorque: Basics Books.

Newman, J. L., Fuqua, D. R., \& Seaworth, T. B. (1989). The role of anxiety in career indecision. Implications for diagnosis and treatment. The Career Development Quarterly, 37, 221-231.

Palmini, A. (2004). O Cérebro e a Tomada de Decisões. Em P. Knapp (Org), Terapia Cognitivo-
Comportamental na Prática Psiquiátrica (pp. 7188). Porto Alegre: Artmed.

Payton, J., Wardlaw, D., Graczyk, P., Bloodworth, M., Tompsett, C., \& Weissberg, R. (2000). Social and emotional learning: A framework for promoting mental health and reducing risk behavior in children and youth. Journal of School Health, 70, 179-185.

Pocinho, M.; Correia, A.; Carvalho, R. \& Silva, C. (2010). Influência do género, da família e dos serviços de psicologia e orientação na tomada de decisão de carreira. Revista Brasileira de Orientação Profissional, 11(2), pp. 201-212.

Raimundo, R. (2012). "Devagar se vai ao longe": Avaliação da eficácia e da qualidade da implementação de um programa de promoção de competências sócioemocionais em crianças. Dissertação de Mestrado, Faculdade de Psicologia. Universidade de Lisboa, Lisboa.

Rassin, E., \& Muris, P. (2005). Indecisiveness and the interpretation of ambiguous situations. Personality and Individual Differences, 39(7), 1285-1291.

Sampson, J. P. Jr., Reardon, R. C., Peterson G. W., \& Lenz, J. G. (2004). Career counseling and services: A cognitive information processing approach. Pacifi c Gorove, CA: Brooks/Cole.

Santos, P. (2005). Indecisão vocacional e indecisão generalizada. Coimbra: Dissertação de mestrado. Universidade de Coimbra. Faculdade de Psicologia e Ciências da Educação.

Savickas, M. L. (1985). Identity in vocational development. Journal of Vocational Behavior, 27, 329-337.

Silva, C. (2011). Estudo de competências emocionais e sua correlação com o auto-conceito. Dissertação de Mestrado. Universidade do Porto.

Super, D. E. (1990). The life span, life space approach to career development. In: D. Brown \& L. Brooks (Orgs.), Career Choice and Development $2^{\mathrm{a}}$ ed., (pp.197-261). San Francisco: Jossey-Bass.

Taveira, M.C. (2000). Exploração e Desenvolvimento Vocacional de Jovens: Estudo sobre as Relações entre a Exploração, a Identidade e a indecisão Vocacional. Braga: Centro de Estudos em Educação e Psicologia, Instituto de Educação e Psicologia.

Taveira, M. C. (2001). O modelo de intervenção vocacional por programas. Lisboa: Casa Pia de Lisboa.

Taveira, M. C. (2005). Comportamento e desenvolvimento vocacional da adolescência. In M. C. Taveira, (Ed.), Temas de psicologia escolar. Uma proposta científico-pedagógica (pp. 143-178). Coimbra, Portugal: Quarteto.

Teixeira, M. (2010). Estudo sobre a eficácia de um programa de inteligência emocional no auto-conceito de alunos do $2^{\circ}$ ciclo do ensino básico. Dissertação de mestrado. Universidade Fernando Pessoa: Porto.

Vaughn, S., \& Hogan, A. (1994). The Social Competence of students with learning disabilities over time: within-individual examination. Journal of Learning Disabilities, 27 (5), 292-303.

Zunker, V.G. (1986). Career Counseling: Applied Concepts of Life Planning (2nd Ed.). California: Brooks/Cole Publishing Company. 